\title{
Dyeing Properties and Analysis by Rp-Hplc-Dad of Silk Fabrics Dyed with Madder (Rubia tinctorum L.)
}

\author{
Karadag Recep ${ }^{1,2 *}$, Torgan Emine ${ }^{2}$ and Erkan Gökhan ${ }^{3}$ \\ ${ }^{1}$ Laboratory for Natural Dyes, Faculty of Fine Arts, Marmara University, Istanbul, Turkey \\ ${ }^{2}$ Turkish Cultural Foundation, Natural Dyes Research and Development Laboratory, Istanbul, Turkey \\ ${ }^{3}$ Gökhan Erkan, Dokuz Eylül University Textile Engineering Department, Izmir, Turkey
}

\begin{abstract}
Madder (Rubia tinctorum L.) has been used for dyeing textiles since the Stone Age. Common madder produces pigments in its roots, such as alizarin, pseudopurpurin, purpurin, munjistin, rubiadin, xanthopurpurin, purpuroxanthin, lucidin, chinizarin, christofin, and antrhagallol. Madder gives a unique red colour to textiles. The aim of this study is to understand the effect of different mordant concentration on silk dyeing by using madder extract. Degummed and bleached, woven silk fabric was used. Alum $\left[\mathrm{KAl}\left(\mathrm{SO}_{4}\right)_{2} \cdot 12 \mathrm{H}_{2} \mathrm{O}\right]$ was used as mordant. All reagents were analytical grade. Silk fabrics were scoured by soap $(35 \% \mathrm{w} / \mathrm{w})$ at $90^{\circ} \mathrm{C}$ for 1.5 hours. Liquor ratio was $100: 1$. Dyeing was performed at $65^{\circ} \mathrm{C}, 100 \%$ owf, for 2 hours. Mordanting procedure was achieved at different mordant ratio, for 2 hours, at $65^{\circ} \mathrm{C}$. All color measurements were performed using Minolta 3600D spectrophotometer (D65 illuminant, specular included, $10^{\circ}$ observer angle). Colour fastness to washing, light, perspiration and rubbing was performed according to ISO 105 C06, ISO 105 B02, ISO 105 E04 and ISO 105 X12 respectively. Each dyed silk fabrics were analysed RP-HPLC-DAD. Semi-quantities of colouring compounds were determined in the dyed silk fabrics, depending on the amounts of mordant metal.
\end{abstract}

Keywords: Madder; Rubia tinctorum L.; Silk fabrics; Colour measurement; Alizarin; Purpurin; Fastness; HPLC-DAD

\section{Introduction}

Natural dyes are obtained from dye plants and dye animals in nature [1-9]. They were the primary colour source of textiles until the mid - to late 19th century [10-13]. For a long time, natural dyes have been used for purposes such as the colouring of wool, mohair, cotton and silk fibres as well as fur and leather [10,11,14-18]. Anthraquinones, naturally occurring in the madder roots (Rubia tinctorum L.), have been used for dyeing fabrics or fibres especially to the colour red and they have also been used as a lake pigment rarely since ancient times [19]. In addition to their antioxidant, antimicrobial, antifungal and hypotensive effects; anthraquinones have also been known for their various effects such as anticancer and skin diseases [20]. Madder (Rubia tinctorum L.) and other alizarin-containing plants belong to the most important group of red dyestuffs found in nature all over the world. Many of these belong to the large plant family of the Rubiaceae [20-23]. The dye plant is mentioned in early literature on dyeing and textiles dyed with a madder type, dated to $3000 \mathrm{BC}$, have been found in Mohenjo-Daro in the Indus valley. Madder type dyestuffs belong to the group of mordant dyes which need a pre-treatment with a metal salt. The metal salts most in use are alum compounds.

The main colouring compounds are alizarin and purpurin. Together with alizarin and purpurin, a number of anthraquinones such as xanthopurpurin, pseudopurpurin, rubiadin and munjistin are present. In the drying process of madder roots, pseudopurpurin is probably converted into purpurin. In addition, the metal compound used for mordanting, such as aluminium or iron, will influence the uptake of the various colouring components [21].

High Performance Liquid Chromatography (HPLC) using DiodeArray Detection (DAD) is ideally suited for identification of natural dyestuffs present in these materials [22-26].

The colour of the fibre is the result of three combined factors: the spectrum of the light source, the spectral reflectivity of the fibre colour, and the spectral sensitivity of the eye. The CIELAB (1976) system was introduced to describe the colour that results from these three factors. The system is a three dimensional space, with coordinate axes $\mathrm{L}^{*}, \mathrm{a}^{*}$ and $\mathrm{b}^{*}$. The $\mathrm{L}^{\star}$ axis denotes the lightness of the colour $\left(\mathrm{L}^{*}\right.$ of 0 corresponds to black, while $L^{\star}$ of 100 denotes white), $a^{*}$ represents the green-red axis ( $a^{\star}$ negative: green, $a^{\star}$ positive: red), and $b^{\star}$ represents the blueyellow axis ( $b^{*}$ negative: blue, $b^{*}$ positive: yellow). Each fibre colour can be represented as a set of values for $\mathrm{L}^{*}, \mathrm{a}^{\star}$, and $\mathrm{b}^{\star}$, and consequently as a point in this colour space [27]. Colour and fastness tests of the natural fibers dyed with different plants is worked by most researches $[28,29]$.

\section{Materials and Methods}

In this study, $100 \%$ silk, sateen weave S 4/1 (3) fabrics that were ready for dyeing were used. The sateen weave used a $4 / 1$ weaving ratio, floating each weft thread under four warp threads, then over one thread, and the rotation used was 3 . The warp density per $\mathrm{cm}$ of the fabric was 160 and the weft density per $\mathrm{cm}$ was 60 . The weight of the fabric was $74 \mathrm{~g} / \mathrm{m}^{2}$. The silk used in this study was obtained from the Armagan Company (Turkey).

All reagents were analytically graded, unless stated otherwise. Madder (Rubia tinctorium L.) was obtained from the Turkish Cultural Foundation, Cultural Heritage Preservation and Natural Dyes Laboratory. The following standard dyes have been used as references: alizarin from Carl Roth (Germany); rubiadin, and purpurin, which were synthesised by the University of Jordan. Alum $\left[\mathrm{KAl}(\mathrm{SO} 4)_{2} \cdot 12 \mathrm{H}_{2} \mathrm{O}\right.$,

*Corresponding author: Karadag Recep, Laboratory for Natural Dyes, Faculty of Fine Arts, Marmara University, Istanbul, Turkey, Tel. +902163262667; Fax: +902163269129; E-mail: rkaradag@marmara.edu.tr

Received January 20, 2014; Accepted January 29, 2014; Published February 02, 2014

Citation: Recep K, Emine T, Gökhan E (2014) Dyeing Properties and Analysis by Rp-Hplc-Dad of Silk Fabrics Dyed with Madder (Rubia tinctorum L.). J Textile Sci Eng 4: 154. doi:10.4172/2165-8064.1000154

Copyright: @ 2014 Recep K, et al. This is an open-access article distributed under the terms of the Creative Commons Attribution License, which permits unrestricted use, distribution, and reproduction in any medium, provided the original author and source are credited. 
Citation: Recep K, Emine T, Gökhan E (2014) Dyeing Properties and Analysis by Rp-Hplc-Dad of Silk Fabrics Dyed with Madder (Rubia tinctorum L.). J Textile Sci Eng 4: 154. doi:10.4172/2165-8064.1000154

Page 2 of 5

hydrochloric acid and methyl alcohol were obtained from Merck (Germany).

\section{The mordanting and dyeing of silk fabrics}

Sixteen sample silk fabrics were cut, which had about $16 \times 20 \mathrm{~cm}$ in size and 2 grams. These fabrics were washed at constant temperature $\left(90^{\circ} \mathrm{C}\right)$ with $35 \%$ soapy water $100: 1$ ratio of the water for 2 hours. Before and after washing the fabrics, the $\mathrm{pH}$ of soapy water was measured. After the washing the fabrics were thoroughly rinsed with the deionised water and allowed to dry. Than except for one fabric, the other 15 samples were weighted separately for the mordanting process again.

Fifteen samples of fabrics, which had different percent of mordant, were mordanted a constant temperature of $65^{\circ} \mathrm{C}$ for 2 hours. After the mordanting process, the fabrics were waited in the mordant solution at room temperature for 24 hours. At the end of this period the fabrics that were mordanted and unmordanted were dyed at a constant temperature of $65^{\circ} \mathrm{C}$ with $100 \%$ madder (Rubia tinctorum L.) according to their weights by mixing for 2 hours.

After the dyeing process the fabrics were allowed to dry at the room temperature $\left(25^{\circ} \mathrm{C}\right)$ after in order of washing at $25^{\circ} \mathrm{C}$ at $45-50^{\circ} \mathrm{C}$ and in finally $25^{\circ} \mathrm{C}$ in deionized water.

\section{Extraction procedure for HPLC analysis}

The extraction of according to the different mordant percent in the dyed silk fabrics with madder were performed with a solution mixture of $\% 37 \mathrm{HCl}: \mathrm{MeOH}: \mathrm{H}_{2} \mathrm{O},\left(2: 1: 1\right.$; v:v:v) for 8 minutes at $100^{\circ} \mathrm{C}$ in open small tubes to extract dyestuffs. After cooling under running cold tap water, the solution was evaporated just to dryness in a water bath at $65^{\circ} \mathrm{C}$ under a gentle stream of nitrogen. The dry residue was dissolved in $200 \mu \mathrm{l}$ of the mixture of $\mathrm{MeOH}: \mathrm{H}_{2} \mathrm{O}(2: 1 ; \mathrm{v}: \mathrm{v})$ and was centrifuged at $4000 \mathrm{rpm}$ for $10 \mathrm{~min}$. 50 to $100 \mu \mathrm{l}$ supernatant was injected into the HPLC apparatus.

\section{HPLC instrumentation}

Chromatographic measurements were carried out using an Agilent 1200 series system (Agilent Technologies, Hewlett-Packard, Germany) including G1322A Degasser, G1311A Quat pump, G1329A autosample, G13166 TCC, and G1315D Diode Array Detector. PDA detection is performed by scanning from 191 to $799 \mathrm{~nm}$ with a resolution of $2 \mathrm{~nm}$, and the chromatographic peaks were monitored at 255, 268, 276, 350, 491, 520, 580 and 620. Column: A Nova Pak C18 analytical column $(39 \times 150 \mathrm{~mm}, 4 \mu \mathrm{m}$, Part No WAT 086344 , Waters $)$ was used. Analytical and guard columns were maintained at $30^{\circ} \mathrm{C}$ and data station was the Agilent Chemstation. Two solvents were utilized for chromatographic separations of the hydrolysed samples. Solvent A:

\begin{tabular}{|c|c|c|c|}
\hline Time (min.) & Flow rate (ml/min) & $\begin{array}{c}\mathbf{H}_{\mathbf{2}} \mathbf{O}-\mathbf{0 , 1} \% \text { TFA } \\
(\mathbf{v} / \mathbf{v})\end{array}$ & $\begin{array}{c}\mathbf{C H}_{3} \mathbf{C N}-\mathbf{0 , 1} \% \text { TFA } \\
(\mathbf{v} / \mathbf{v})\end{array}$ \\
\hline 0.0 & 0.5 & 95 & 5 \\
\hline 1.0 & 0.5 & 95 & 5 \\
\hline 20 & 0.5 & 70 & 30 \\
\hline 25 & 0.5 & 40 & 60 \\
\hline 28 & 0.5 & 40 & 60 \\
\hline 33 & 0.5 & 5 & 95 \\
\hline 35 & 0.5 & 5 & 95 \\
\hline 40 & 0.5 & 95 & 5 \\
\hline 45 & 0.5 & 95 & 5 \\
\hline
\end{tabular}

Table 1: HPLC analysis is performed using the following gradient elution.

\begin{tabular}{|c|c|c|c|}
\hline Trial No. & $\begin{array}{l}\text { Percent of alum } \\
\text { mordant }\end{array}$ & $\begin{array}{l}\text { Identified } \\
\text { dyestuff }\end{array}$ & $\begin{array}{l}\text { Percent of d } \\
\text { yestuff }\end{array}$ \\
\hline \multirow{3}{*}{1} & \multirow{3}{*}{0} & alizarin & 70.979 \\
\hline & & purpurin & 25.890 \\
\hline & & rubiadin & 3.130 \\
\hline \multirow{3}{*}{2} & \multirow{3}{*}{1} & alizarin & 63.878 \\
\hline & & purpurin & 34.142 \\
\hline & & rubiadin & 1.981 \\
\hline \multirow{3}{*}{3} & \multirow{3}{*}{2} & alizarin & 60.649 \\
\hline & & purpurin & 37.685 \\
\hline & & rubiadin & 1.666 \\
\hline \multirow{3}{*}{4} & \multirow{3}{*}{3} & alizarin & 67.247 \\
\hline & & purpurin & 30.794 \\
\hline & & rubiadin & 1.959 \\
\hline \multirow{3}{*}{5} & \multirow{3}{*}{4} & alizarin & 62.223 \\
\hline & & purpurin & 36.015 \\
\hline & & rubiadin & 1.762 \\
\hline \multirow{3}{*}{6} & \multirow{3}{*}{6} & alizarin & 65.296 \\
\hline & & purpurin & 32.699 \\
\hline & & rubiadin & 2.005 \\
\hline \multirow{3}{*}{7} & \multirow{3}{*}{9} & alizarin & 71.339 \\
\hline & & purpurin & 26.876 \\
\hline & & rubiadin & 1.785 \\
\hline \multirow{3}{*}{8} & \multirow{3}{*}{12} & alizarin & 62.864 \\
\hline & & purpurin & 35.024 \\
\hline & & rubiadin & 2.112 \\
\hline \multirow{3}{*}{9} & \multirow{3}{*}{14} & alizarin & 53.192 \\
\hline & & purpurin & 45.145 \\
\hline & & rubiadin & 1.664 \\
\hline \multirow{3}{*}{10} & \multirow{3}{*}{18} & alizarin & 62.336 \\
\hline & & purpurin & 35.583 \\
\hline & & rubiadin & 2.081 \\
\hline \multirow{3}{*}{11} & \multirow{3}{*}{21} & alizarin & 57.288 \\
\hline & & purpurin & 41.123 \\
\hline & & rubiadin & 1.590 \\
\hline \multirow{3}{*}{12} & & alizarin & 59.347 \\
\hline & 24 & purpurin & 38.790 \\
\hline & & rubiadin & 1.862 \\
\hline & & alizarin & 66.263 \\
\hline 13 & 27 & purpurin & 31.325 \\
\hline & & rubiadin & 2.411 \\
\hline & & alizarin & 55.425 \\
\hline 14 & 30 & purpurin & 42.438 \\
\hline & & rubiadin & 2.137 \\
\hline & & alizarin & 73.270 \\
\hline 15 & 33 & purpurin & 24.094 \\
\hline & & rubiadin & 2.636 \\
\hline & & alizarin & 56.099 \\
\hline 16 & 36 & purpurin & 41.942 \\
\hline & & rubiadin & 1.959 \\
\hline
\end{tabular}

Table 2: Variation semi quantities percent of alizarin, purpurin and rubiadin are in the dyed fabrics.

$\mathrm{H}_{2} \mathrm{O}-0.1 \%$ TFA and solvent $\mathrm{B}: \mathrm{CH}_{3} \mathrm{CN}-0.1 \%$ TFA. The flow rate was 0.5 $\mathrm{mL} / \mathrm{min}$, and following elution program was applied (Table 1).

\section{Colour measurements of silk fabrics}

All colour measurements were performed using Minolta 3600D spectrophotometer (D65 illuminate, specular included, $10^{\circ}$ observer angle). The spectrophotometer was equipped with software, which was able to automatically calculate $\mathrm{CIEL}^{\star} \mathrm{a}^{\star} \mathrm{b}^{\star}$ and colour strength (K/S) 


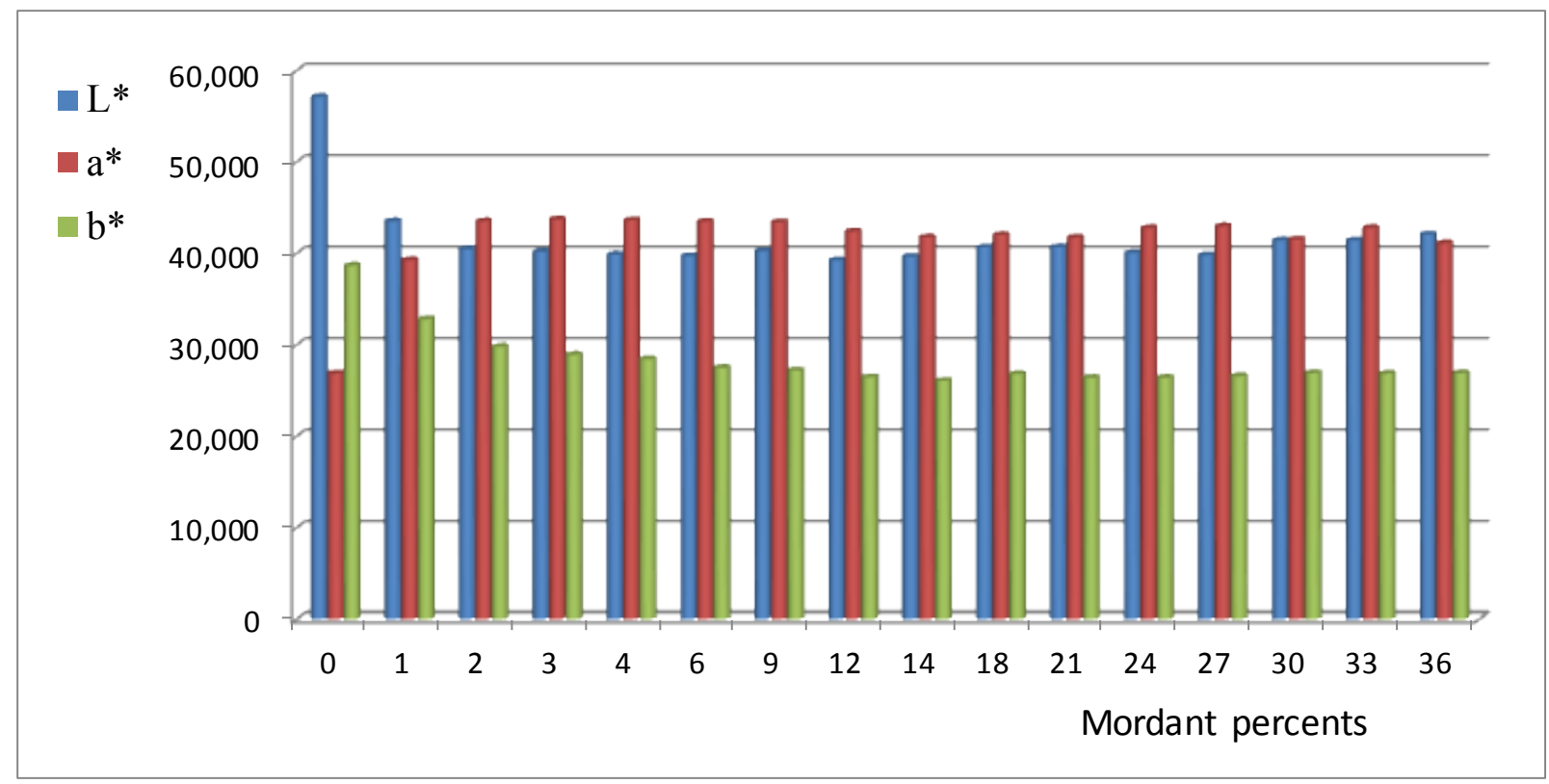

Figure 1: Colour Strength Values of Fabrics.

\begin{tabular}{|l|c|c|c|c|c|c|}
\hline Trial No. & $\begin{array}{c}\text { Mordant } \\
\text { percentage (w/w) }\end{array}$ & $\mathbf{L}^{*}$ & $\mathbf{a}^{*}$ & $\mathbf{b}^{*}$ & $\mathbf{C}^{*}$ & $\mathbf{H}^{\circ}$ \\
\hline 1 & 0 & 57.151 & 26.875 & 38.681 & 47.101 & 55.209 \\
\hline 2 & 1 & 43.539 & 39.285 & 32.810 & 51.184 & 39.867 \\
\hline 3 & 2 & 40.488 & 43.541 & 29.809 & 52.767 & 34.396 \\
\hline 4 & 3 & 40.218 & 43.751 & 28.927 & 52.449 & 33.472 \\
\hline 5 & 4 & 39.882 & 43.643 & 28.450 & 52.097 & 33.099 \\
\hline 6 & 6 & 39.740 & 43.517 & 27.511 & 51.484 & 32.301 \\
\hline 7 & 9 & 40.268 & 43.435 & 27.218 & 51.248 & 32.079 \\
\hline 8 & 12 & 39.266 & 42.424 & 26.480 & 50.010 & 31.972 \\
\hline 9 & 14 & 39.672 & 41.771 & 26.078 & 49.243 & 31.977 \\
\hline 10 & 18 & 40.688 & 42.048 & 26.824 & 49.876 & 32.536 \\
\hline 11 & 21 & 40.702 & 41.738 & 26.441 & 49.409 & 32.354 \\
\hline 12 & 24 & 40.065 & 42.789 & 26.426 & 50.292 & 31.699 \\
\hline 13 & 27 & 39.803 & 42.994 & 26.605 & 50.560 & 31.749 \\
\hline 14 & 30 & 41.439 & 41.551 & 26.930 & 49.514 & 32.948 \\
\hline 15 & 33 & 41.430 & 42.819 & 26.866 & 50.549 & 32.106 \\
\hline 16 & 36 & 42.097 & 41.129 & 26.917 & 49.155 & 33.203 \\
\hline
\end{tabular}

Table 3: Colorimetric values of fabrics.

values from the reflectance values at the appropriate-wavelength for each dyeing.

Colour strengths of fabrics were determined by using the KubelkaMunk formula (Eq. 1), which is shown below.

$\mathrm{K} / \mathrm{S}(1-\mathrm{R})^{2} / 2 \mathrm{R}$

where,

$\mathrm{K}$ is the scattering coefficient

$\mathrm{S}$ is the absorption coefficient

$\mathrm{R}$ is the reflectance

\section{Fastness measurements of silk fabrics}

Washing fastness, light fastness and rubbing fastness of the dyed silk fabrics were performed according to ISO 105 C06, ISO 105 B02,
ISO 105-X12 respectively [30-33]. The specific tests were applied by using the following instruments: Atlas Xenotest Alpha for light fastness, Atlas rubbing fastness tester and Atlas Linitest for washing fastness. The changes in shades and staining to adjacent multi fibres fabrics and rubbing fastness fabrics were related to the standard Grey Scale rating (where 1 is poor and 5 is excellent). The changes in shades under artificial light were evaluated according to standard blue wool fabrics (SDC) protocols. ECE non-phosphate standard detergent was used in washing fastness trials.

\section{Results}

Each dyed silk fabrics were analysed using a RP-HPLC-DAD. Quantities of colouring compounds were determined in the dyed silk fabrics, depending on the amounts of mordant metal (Table 2). Table 2 shows colorimetric values of samples. The darkest hue was obtained at $12 \%$ of mordant concentration. Redness of fabrics was increased by mordanting. Highest $\mathrm{a}^{*}$ value (redness) was obtained at $3 \%$ mordant concentration. Vividness of fabrics was increased by adding mordant. The results were seen suitable with $[17,23]$.

Colour strength values of fabrics are depicted in Figure 1. If the percent area of spectra of each dye is compared with the colour strength (Kubelka-Munk) values, a correlation between the purpurin concentration and colour strength appears. The color strength of the fabrics was increased with the increasing of purpurin concentration. However increase of concentration of alizarin yields decreasing of the colour strength values. This fact may be due to the amount of hydroxyl groups of both alizarin and purpurin. Alizarin has two hydroxyl groups and purpurin has three hydroxyl groups. Thus the alum can have more chance to bind with purpurin rather than the alizarin. Mordant addition increases the colour strength of the fabrics. The highest colour strength was obtained at $4 \%$ of mordant concentration.

Colorimetric values of fabrics are presented at Table $3 . \mathrm{L}^{*}$ values were compatible with the colour strength values of the highest lightness and was observed in the case of non-mordant fabric due to the binding effect of mordant. Highest red colour was obtained in the case of $3 \%$ 
Citation: Recep K, Emine T, Gökhan E (2014) Dyeing Properties and Analysis by Rp-Hplc-Dad of Silk Fabrics Dyed with Madder (Rubia tinctorum L.) J Textile Sci Eng 4: 154. doi:10.4172/2165-8064.1000154

Page 4 of 5

\begin{tabular}{|c|c|c|c|c|c|c|c|c|c|c|c|c|c|c|c|c|c|c|c|c|c|c|c|c|}
\hline \multirow{3}{*}{$\begin{array}{l}\text { Trial } \\
\text { No. }\end{array}$} & \multirow{3}{*}{$\begin{array}{c}\text { Fastness } \\
\text { to Light }\end{array}$} & \multirow{2}{*}{\multicolumn{2}{|c|}{$\begin{array}{l}\text { Rubbing } \\
\text { Fastness }\end{array}$}} & \multicolumn{7}{|c|}{ Colour Fastness to Washing } & \multicolumn{7}{|c|}{ Colour Fastness to Perspiration (Acidic) } & \multicolumn{7}{|c|}{ Colour Fastness to Perspiration (Basic) } \\
\hline & & & & \multirow{2}{*}{$\begin{array}{l}\text { Colour } \\
\text { Change }\end{array}$} & \multicolumn{6}{|c|}{ Bleeding } & \multirow{2}{*}{$\begin{array}{l}\text { Colour } \\
\text { Change }\end{array}$} & \multicolumn{6}{|c|}{ Bleeding } & \multirow{2}{*}{$\begin{array}{l}\text { Colour } \\
\text { Change }\end{array}$} & \multicolumn{6}{|c|}{ Bleeding } \\
\hline & & Dry & Wet & & CA & Co & PES & PA & PAC & Wo & & CA & Co & PES & PA & PAC & Wo & & CA & Co & PES & PA & PAC & Wo \\
\hline 1 & $3-4$ & 5 & 4 & $2-3$ & 4 & $3-4$ & $3-4$ & 3 & $4-5$ & $2-3$ & $1-2$ & 2 & $2-3$ & $3-4$ & $1-2$ & 4 & $1-2$ & $1-2$ & 2 & 2 & 3 & $1-2$ & $2-3$ & 1 \\
\hline 2 & 4 & 2 & 2 & 3 & 3 & 4 & 4 & 3 & $4-5$ & $2-3$ & $3-4$ & $2-3$ & $2-3$ & 4 & $1-2$ & 4 & $1-2$ & 3 & 2 & 2 & 3 & $1-2$ & $2-3$ & 1 \\
\hline 3 & 5 & $3-4$ & $3-4$ & 4 & 3 & 4 & 4 & $3-4$ & $4-5$ & 3 & 4 & 3 & 3 & 4 & $2-3$ & 4 & $2-3$ & 3 & $2-3$ & $2-3$ & $3-4$ & 2 & $3-4$ & $2-3$ \\
\hline 4 & $4-5$ & 4 & $3-4$ & $4-5$ & 4 & 4 & $4-5$ & 3-4 & $4-5$ & 3 & $4-5$ & $3-4$ & $3-4$ & $4-5$ & $2-3$ & $4-5$ & 3 & 4 & $2-3$ & $2-3$ & 4 & 2 & 4 & $2-3$ \\
\hline 5 & 5 & $4-5$ & 4 & $4-5$ & 4 & 4 & $4-5$ & 4 & 5 & 4 & $4-5$ & $3-4$ & $3-4$ & $4-5$ & 3 & $4-5$ & $3-4$ & $4-5$ & $2-3$ & $2-3$ & 4 & 2 & 4 & $2-3$ \\
\hline 6 & 6 & $4-5$ & $4-5$ & $4-5$ & 4 & $4-5$ & $4-5$ & 4 & 5 & 4 & $4-5$ & 3-4 & 4 & $4-5$ & 3 & $4-5$ & $3-4$ & $4-5$ & $2-3$ & $2-3$ & 4 & 2 & 4 & $2-3$ \\
\hline 7 & $5-6$ & $4-5$ & $4-5$ & $4-5$ & 4 & $4-5$ & $4-5$ & 4 & 5 & 4 & $4-5$ & $3-4$ & 4 & $4-5$ & 3 & $4-5$ & $3-4$ & $4-5$ & $2-3$ & $2-3$ & 4 & 2 & 4 & $2-3$ \\
\hline 8 & $5-6$ & $4-5$ & $4-5$ & $4-5$ & 4 & $4-5$ & $4-5$ & 4 & 5 & 4 & $4-5$ & $3-4$ & 4 & $4-5$ & 3 & $4-5$ & $3-4$ & $4-5$ & $2-3$ & $2-3$ & 4 & 2 & 4 & $2-3$ \\
\hline 9 & $5-6$ & $4-5$ & 4 & $4-5$ & 4 & $4-5$ & $4-5$ & 4 & 5 & 4 & $4-5$ & $3-4$ & 4 & $4-5$ & 3 & $4-5$ & $3-4$ & $4-5$ & $2-3$ & $2-3$ & 4 & 2 & 4 & $2-3$ \\
\hline 10 & $5-6$ & $4-5$ & $4-5$ & $4-5$ & 4 & $4-5$ & $4-5$ & 4 & 5 & 4 & $4-5$ & $3-4$ & 4 & $4-5$ & 3 & $4-5$ & $3-4$ & $4-5$ & $2-3$ & $2-3$ & 4 & 2 & 4 & $2-3$ \\
\hline 11 & $5-6$ & $4-5$ & $4-5$ & $4-5$ & 4 & $4-5$ & $4-5$ & 4 & 5 & 4 & $4-5$ & 4 & 4 & $4-5$ & 3 & $4-5$ & $3-4$ & $4-5$ & $2-3$ & $2-3$ & $3-4$ & 2 & $3-4$ & $2-3$ \\
\hline 12 & $5-6$ & $4-5$ & $4-5$ & $4-5$ & 4 & $4-5$ & $4-5$ & 4 & 5 & 4 & $4-5$ & $3-4$ & 4 & $4-5$ & 3 & $4-5$ & $3-4$ & $4-5$ & $2-3$ & $2-3$ & 4 & 2 & 4 & $2-3$ \\
\hline 13 & $5-6$ & $4-5$ & 4 & $4-5$ & 4 & $4-5$ & $4-5$ & 4 & 5 & 4 & $4-5$ & $3-4$ & 4 & $4-5$ & 3 & $4-5$ & $3-4$ & $4-5$ & $2-3$ & $2-3$ & 4 & 2 & 4 & $2-3$ \\
\hline 14 & 5 & $4-5$ & 4 & $4-5$ & 4 & $4-5$ & $4-5$ & $3-4$ & 5 & $3-4$ & $4-5$ & 3 & $2-3$ & $4-5$ & $2-3$ & $4-5$ & 3 & $4-5$ & $2-3$ & $2-3$ & 3-4 & 2 & $3-4$ & $2-3$ \\
\hline 15 & $5-6$ & $4-5$ & $4-5$ & $4-5$ & 4 & $4-5$ & $4-5$ & 3-4 & 5 & $3-4$ & $4-5$ & 3 & 3 & $4-5$ & 3 & $4-5$ & $3-4$ & $4-5$ & 3 & 3 & 4 & 3 & 4 & 3 \\
\hline 16 & $5-6$ & $4-5$ & $4-5$ & $4-5$ & 4 & $4-5$ & $4-5$ & 3-4 & 5 & $3-4$ & $4-5$ & 3 & 3 & $4-5$ & 3 & $4-5$ & 3 & $4-5$ & 3 & 3 & 4 & 3 & 4 & 3 \\
\hline
\end{tabular}

PA: Polyamide, WO: Wool, PAC: Polyacrylic, PES: Polyester, CO: Cotton, CA: Cellulose.

Table 4: Fastness Properties of Fabrics.

mordant concentration. However no significant variation was observed between the concentration levels of mordant. As a general statement alizarin and purpurin have a red colour. Variations at the amounts of alizarin and purpurin did not affect the redness of the fabrics. However yellowness of the fabrics was affected by rubiadin concentration. Decreasing of concentration of rubiadin yielded the decreasing of $b^{*}$ values of fabrics. The highest $b^{\star}$ value was observed at non-mordant dyeing.

Fastness properties of fabrics are listed at Table 4 . Wet fastness properties are related to binding mechanism of dye into fibre. Thus, addition of mordant gave higher fastness results than the non-mordant dyeing. Washing fastness results increased with increasing of mordant concentration. However poor results were observed in the case of basic perspiration fastness tests. This fact can be due to the exceed hydroxyl ions in the perspiration solution. When compared with basic perspiration fastness test results, relatively better results were observed for acidic perspiration fastness tests. According to the all fastness results, the best result is dyed fabric with $6 \%$ alum mordant.

This study shows that the colour strength and colorimetric values of dyed fabrics are strongly affected by colouring components of natural dye solution. Colour strength values increased by increasing of amount of alizarin. Yellowness $\left(b^{*}\right)$ of the fabrics were changed by amount of rubiadin. Future studies in this field should focus on the role of the each component of the natural dyes. Affinity and dye uptake of each component of natural dyes should be studied.

\section{Acknowledgement}

This work was supported by the Turkish Cultural Foundation (TCF) Cultural Heritage Preservation and Natural Dyes Laboratory and Marmara University BABKO project (Fen-D-150513-0191) are gratefully acknowledged. (http://www. turkishculturalfoundation.org,http://www.tcfdatu.org)

\section{References}

1. Surowiec I, Gawryś JO, Biesaga M, Trojanowicz M, Hutta M, et al. (2003) Identification of natural dyestuff in archaeological Coptic textiles by HPLC with fluorescence detection. Anal Letters 36: 1211-1229.

2. Rafaëlly L, Héron S, Nowik W, Tchapla A (2008) Optimisation of ESI-MS detection for the HPLC of anthraquinone dyes. Dyes Pigments 77: 191-203.
3. Clementi C, Doherty B, Gentili PL, Miliani C, Romani A, et al. (2008) Vibrational and electronic properties of painting lakes. Appl Phys A 92: 25-33.

4. Crews PC (1987) The fading rates of some natural dyes. Studies in Conservation 32: 65-72.

5. Schweppe H (1980) Identification of Dyes on Old Textiles. J Am Inst Conserv 19: $14-23$

6. Wouters J, ChirinosNR(1992) Dye Analysis of Pre-Columbian Peruvian Textiles With High-Performance Liquid Chromatography and Diode-Array Detection. J Am Inst Conserv 31: 237-255.

7. Taylor GW (1983) Detection and identiflcation of dyes on Anglo-Scandinavian textiles. Studies in Conservation 28: 153-160.

8. Ali S, Nisar N, Hussain T (2007) Dyeing properties of natural dyes extracted from eucalyptus. J Textile Inst 98: 559-562.

9. Mayolo AD (1989) Peruvian Natural Dye Plants. Econ Bot 43: 183-189.

10. Peggie DA, Hulme AN, McNab H, Quye A (2008) Towards the identification of characteristic minor components from textiles dyed with weld (Reseda luteola L.) and those dyed with Mexican cochineal (Dactylopiuscoccus Costa) Microchim Acta 162: 371-380.

11. Cristea D, Bareau I, Vilarem G (2003) Identification and quantitative HPLC analysis of the main flavonoids present in weld (Reseda luteola L.). Dyes Pigments 57: 267-272.

12. Cerrato A, Santis DD, Moresi M (2002) Production of luteolin extracts from Reseda luteola and assessment of their dyeing properties. Sci Food Agric 82: 1189-1199.

13. Moiteiro C, Gaspar H, Rodrigues Al, Lopes JF, Carnide V (2008) HPLC quantification of dye flavonoids in Reseda luteola L. from Portugal. J Sep Sci 31: 3683-3687.

14. Farizadeh K, Montazer M, Yazdanshenas ME, Rashidi A, Malek RMA (2009) Extraction, identification and sorption studies of dyes from madder on wool. $J$ Appl Poly Sci 113: 3799-3808.

15. Colombini MP, Andreotti A, Baraldi AC, Degano I, Łucejko JJ (2007) Colour fading in textiles: A model study on the decomposition of natural dyes. Microchem J 85: 174-182.

16. Cristea D,Vilarem G (2006) Improving light fastness of natural dyes on cotton yarn. Dyes Pigments 70: 238-245.

17. Deveoglu O, Torgan E, Karadag R (2011) High-performance liquid chromatography of some natural dyes: analysis of plant extracts and dyed textiles. Color Tech 128: 133-138. 
Citation: Recep K, Emine T, Gökhan E (2014) Dyeing Properties and Analysis by Rp-Hplc-Dad of Silk Fabrics Dyed with Madder (Rubia tinctorum L.). J Textile Sci Eng 4: 154. doi:10.4172/2165-8064.1000154

18. Deveoglu O, Erkan G, Torgan E, Karadag R (2012) The evaluation of procedures for dyeing silk with buckthorn and walloon oak on the basis of colour changes and fastness characteristics. Coloration Technologies 129: 223-231.

19. Judy H, Sally P (2009) Natural Dyes. The Crowood Press Ltd, RamsburyMarlborough, UK.

20. Karadag R, Torgan E,Yurdun T( 2010) Formation and HPLC analysis of the natural lake pigment obtained from madder (Rubia tinctorum L.). Rew Anal Chem 29: 1-12.

21. Judith H, de Graaff H (2004) The Colourful Past. Archetype Publications, Abegg-Stiftung, Switzerland.

22. Karadag R(2007) Dogal Boyamacilik. Ankamat Matbaacılık San. Ltd. Sti. Ankara.

23. Deveoglu O, Sahinbaskan BY, Torga E, Karadag R (2012) Investigation on colour, fastness properties and HPLC-DAD analysis of silk fibres dyed with Rubia tinctorium L. and Quercusithaburensis Decaisne. Coloration Technologies 128: 364-370

24. Deveoglu O, Torgan E, Taskopru T,Karadag R (2010) SEM-EDX/HPLC analysis and production of natural pigments from Quercusithaburensis with $\mathrm{Al}^{3+}, \mathrm{Fe}^{2+}$ and $\mathrm{Sn}^{2+}$ metals. Proceeding $6^{\text {th }}$ Conference on Medicinal and Aromatic Plants of Southeast European Countries, Antalya, Turkey.

25. Deveoglu O, Torgan E, Karadag R (2010) Characterization of Colouring Matters by HPLC-DAD and Colour Measurements, Preparation of Lake Pigments with Ararat kermes (Porphyrophorahameli Brand). Jordan J Chem 5: 307-315.

26. Deveoglu O, Torgan E,Karadag R (2010) Identification of Dyestuffs in the Natural Pigments Produced with $\mathrm{Al}^{3+}, \mathrm{Fe}^{2+}$ and $\mathrm{Sn}^{2+}$ Mordant Metals from Cochineal (Dactylopiuscoccus Costa) and Walloon oak (Quercusithaburensis Decaisne) by HPLC-DAD. Asian J Chem 22: 7021-7030.

27. Krikken JB, Zijp JR, Huysmans MC (2008) Monitoring dental erosion by colour measurement: an in vitro study. J Dent 36: 731-735.

28. Ali AK, Naeem I, Shahid A, Muhammad A, Fatima B, et al. (2014) Extraction of natural dye from red calico leaves: Gamma ray assisted improvements in colour strength and fastness. Dyes and Pigments 103: 50-54.

29. Fazal-ur-Rehman, Shahid A, Muhammad S, ljaz AB, Faiza N, et al. (2013) Effect of gamma radiation on dyeing of cotton with aqueous extracts of irradiated Onion leaves (Allium cepa). Rad Phy Chem 92: 71-75.

30. ISO 105-C06 (A1S) (2010) Textiles-Tests for colour fastness-PartC06: Colour fastness to domestic and commercial laundering. Basel, AIS.

31. ISO 105-B02 (2013) Textiles-Tests of colour fastness-Part B02: Colour fastness to artical light: Xenon arc fading lamp test. Basel, AIS.

32. ISO 105-X12 (2002) Textiles-Tests for colour fastness of textiles, Basel.

33. ISO 105-E04 (2013) Textiles-Tests for colour fastness of textiles-Colour fastness to perspiration. Basel, AIS. 